\title{
ORGANSING LEARNERS' GUIDED SELF-STUDY IN TEACHING MATH IN VIETNAMESE HIGH SCHOOLS
}

\author{
Quang Duc Pham ${ }^{1}$, \\ Lam Hanh Thi Bui ${ }^{2,+}$
}

\section{Article History}

Received: 08 October 2020

Accepted: 14 November 2020

Published: 30 December 2020

\section{Keywords}

Self learning, self-study with guidance, students, math

\author{
${ }^{1}$ Vietnam National Institute of Education Science; \\ ${ }^{2}$ Thai Nguyen University of Education, Vietnam \\ ${ }^{+}$Corresponding author •Email: lambth@tnue.edu.vn
}

\section{INTRODUCTION}

In Vietnamese high schools, self-study plays a very important role in helping learners to deeply understand, expand, consolidate and memorise lessons profoundly based on the ability to self-analyze, synthesize and apply known knowledge in solving new learning tasks. With the development of science and technology, the goal of the 2018 general education program has changed from equipping knowledge to developing learners' qualities and competencies, requiring learners to be active and proactive and to have suitable self-study method.

It is shown that self-study guidance for high school learners has not received adequate attention from teachers, and students' self-studying skills are still limited. Teachers' guidance is necessary for students to study effectively on their own. This article presents some issues on guided self-studying and the method to guide students with math instructions in high schools.

\section{LITERATURE REVIEW}

In Vietnam, guided self-studying has become a research focus among many local and international authors, approached in a number of different directions:

- The first direction: Guided self-studying is considered an individual way of learning. For example, Knowles (1975) argues that: Guided self-studying is a process where individuals, with or without the support of others, identify needs, set goals, and choose resources to learn, select and use learning strategies and appropriate assessment of learning outcomes. Candy (1991) defines: Guided self-studying refers to autonomy in learning, controlled learners, and guided learning; self-direction, self-study, self-responsibility for learning. According to Dang Thi Oanh (2007): Guided self-study is a way of learning based on guided self-study materials (including content and how to acquire knowledge and evaluate results), where learners can educate themselves. Nguyen Duy Can (2010) mentions guided modular self-studying.

- The second direction: Guided self-studying is regarded as a teaching method. For example, Hiemstra (1994) refers to guided self-studying as a teaching process that affects each learner.

- The third direction: Guided self-studying is an approach of training. Nguyen Canh Toan (2001) emphasizes that: Guided self-studying mainly provides the way of thinking and learning to acquire knowledge, as well as selfadjusting the process of knowledge acquisition. The Ministry of Education and Training (2002) specifies that selfstudy with guidance is a form of informal education in which learners have to self-study materials and textbooks to acquire knowledge and practice skills with teachers' guidance.

\section{RESEARCH METHODS AND RESULTS}

\subsection{Research methods}


In this article, the following research methods are employed: Theoretical research method: analysis and synthesis of existing literature; Empirical research method: investigating educational practice; Summarizing and applying experience: planning and proposing solutions, and developing implementation steps.

\subsection{Research results}

3.2.1. Theoretical background

\subsubsection{The concept of self-study}

There are many different views on self-study. According to Educational Dictionary: Self-study is the process of acquiring scientific knowledge and practicing practical skills by oneself (Hoang Phe, 2018). "Self-study is to utilise our senses to acquire information, automatically brainstorm, use intellectual abilities (observe, compare, analyze, synthesize) and sometimes even muscles (with compulsory tools) along with one's qualities, motives, emotions, human views, worldview to acquire a certain field of knowledge, certain skills, qualities of humanity or community and make them one's attribute" (Nguyen Canh Toan, 2001a, p. 407).

In this paper, it can be understood that: Self-study is a process of autonomous, active and independent learning to achieve knowledge. That means the process of self-study is self-controling, self-occupying knowledge to memorise, understand and apply knowledge. Therefore, from the structural perspective, self-study possesses the following characteristics: - Learning motivation: the demand and excitement to engage students to the learning process and maintain positivity, helping them realize the role and meaning of self-study; - Orientation: Helping students to identify and realize the goals of their learning activities (answering the question: What to study for?); - Content and methods: the system of knowledge, skills, key techniques to learn and how to master them (answering the question: What to learn? How to learn?); - Learning competencies: the ability to focus, intellectual and practical capacities; - Self-assessment capacity: the ability to self-evaluate self-study results as the basis for the next activities.

Based on the level of learning autonomy, there are several basic forms of self-study as follows: - Self-study without any teachers: through documents, practical inquiry, from others' experience to self-acquire knowledge. One of the challenges of this form is that students may easily become discouraged and fail to maintain study by themselves; - Self-study with instructional documents with the contents, how to construct knowledge, how to check the results after each section. In case of failure, learners can research, supplement, redo until success (e.g with computer softwares); - Practise some learning activities by themselves with the guidance of teachers in class.

\subsubsection{The role of self-study}

Self-study also plays a key role in improving learning capacity and acquiring new knowledge. In the self-study process, students encounter many new problems which requires suitable solutions effectively stimulates and develops their intellectual capacities. Moreover, self-study also plays an important role in educating and forming learners' personality. Self-learning trains students the habits of independent thinking, solving challenges independently in their learning and in life. It also helps students to be more confident. Moreover, self-study nurtures students' learning desire, curiosity, thirst for knowledge, success in learning and life, as well as their ambitions and dreams.

Self-study helps each person to study actively throughout their lives, adapt to changes and developments of society. Therefore, self-study should not be limited to the lessons in class, with the direct guidance of teachers. If learners are trained with methods and skills of self-studying to apply the knowledge they have learned into practice flexibly, they will develop the passion for learning and further excel in their learning.

3.2.1.3. Concept of guided self-study

It can be stated that guided self-study is a guide to self-study and gain knowledge with the teacher's direct or indirect instructions through learning materials such as: guided self-study materials, reference materials, electronic lesson plans, etc. Guided self-study documents not only present the content of knowledge but also inform students on self-study methods to discover and solve problems, self-assess one's own learning results. Using guided selflearning materials, teachers can orient and organize students to explore new knowledge; students actively master methodology to acquire knowledge. With guided self-study, students learn at a pace and schedule consistent with their own abilities. As a result, students have the opportunity to think independently, express their own opinions and develop competencies of collaboration, self-assessment and peer assessment.

With the above understanding, guided self-study has the following basic characteristics: - Students are the subject of the cognitive process, learning based on their own ability, pace, and progress; - Self-study in an proactive, active and oriented process based on interaction, exchange, and sharing; - Students are capable of learning through learning 
guides, teacher-designed activities to self-acquire knowledge; - Teachers are companions with students for timely support and guidance; In class: guided self-study can achieve positive results through group activities.

\subsubsection{Forms of guided self-study in teaching Mathematics in high schools}

- Self-study with guidance in the classroom: According to Nguyen Canh Toan et al. (2001b) and Nguyen Dinh Xuan (2000), students' guided self-study process in the classroom in high schools usually consists of 04 stages:

Stage 1: Self-study. Students self-study and perform a number of learning activities under instructions (of teachers of guided self-study materials) based on their existing knowledge, thereby forming their own knowledge.

Stage 2: Sharing and discussion. Students share the results, observations, and feelings through learning activities with their peers and discuss with teachers. Depending on the content and learning tasks, students can express through different ways, such as: summarizing, proposing problem-solving ideas; presenting solutions; discussing new ideas with their friends and teachers.

Stage 3: Self-examination and adjustment to form knowledge. After the activities in phase 2, students compare, check, and adjust initial knowledge to form new knowledge and skills.

Stage 4: Self-applying knowledge. Based on the acquired knowledge, students apply to different situations in the subject, as well as in practice.

- Guided self-study outside the classroom: Guided self-study outside the classroom enables students to learn anytime, anywhere. Today, with the help of information technology, students can self-study using self-study guide. Besides, students can self-study through the tasks assigned by the teacher. In the self-study process, students can receive support from teachers through emails, facebook, zalo, etc. and other support sources.

3.2.3. Organizing students' guided self-study in teaching Mathematics in high schools

To improve teaching quality, teachers need to guide students to study effectively on their own. The self-study process will be difficult to succeed without the teachers' guidance. On the contrary, the teaching process will be ineffective without students' sufficient self-study competence. Therefore, teachers need to combine teaching and self-learning activities in the teaching process.

Instructional materials, an indispensable element in the process of teaching to promote students' guided selfstudy, are designed to help students learn by themselves, demonstrating the teacher's pedagogical intentions, including teaching and learning activities, instructions and summaries necessary for learners. Activities in instructional materials are often divided into units of knowledge and activities with specific purposes. The guided self-study materials closely follow learners' self-study process, usually consisting of 03 parts: - Activities that allow students to share and discuss learners' existing knowledge with their peers and teachers; - Practical activities are examples, exercises that encourage students to reinforce and turn learned knowledge into their own, consolidating knowledge for learners; - Application activities: Help students apply and expand knowledge learned in learning, or handle real-life situations.

Using the instructions in the self-study guide, students conduct learning activities, report the results to teachers, eventually constructing knowledge. Teachers have support when students have learning difficulties. In the learning guides, teachers need to design hierarchical learning activities to match the abilities of individual students in learning concepts, theorems and solving exercises, help students learn by themselves and construct their own knowledge.

An example of guided self-study procedure in the classroom for the following problem is as follows: "In the coordinate system Oxy, given a score $\mathrm{M}(1 ; 2)$. Write a linear equation that goes through point $\mathrm{M}$ and cuts two coordinate axes at two points A and B respectively so that $\mathrm{OA}=\mathrm{OB}$ ".

In the above problem, teachers need to design learning activities following the guided self-study stages as follows:

Stage 1: Self-study. Teachers let students study the problem using G. Polya's 4-step process (2010), specifically:

Step 1: Identifying the problem: - What is given in the problem? (students' expected answer: coordinate system Oxy; point $\mathrm{M}(1 ; 2), \mathrm{OA}=\mathrm{OB}$, with points A, B on the coordinate axes); - What is the expected outcome? (students' expected answer: The straight line equation passing point $\mathrm{M}(1 ; 2)$ and two points $\mathrm{A}, \mathrm{B})$; - Is there a similar problem to the one given? (students' expected answer: The line goes through two points on two coordinate axes, or through a point with the coefficient of angle $\mathrm{k}$ ).

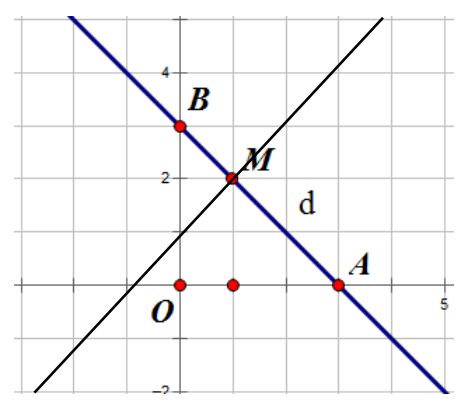

Figure 1 
Step 2: Finding the solution: - Convert the problem to a familiar one. (students' expected answer: Supposed we have line d passing through point $\mathrm{M}$ and cutting $\mathrm{Ox}$ at $\mathrm{A}$, cutting $\mathrm{Oy}$ at $\mathrm{B}$, so that $\mathrm{OA}=\mathrm{OB}$ (see Figure 1), it is easy to see the triangle $\mathrm{OAB}$ is isosceles square. What is the angle created by $\mathrm{d}$ with $\mathrm{Ox}$ ? In other words, what angle does the line $\mathrm{d}$ passing through the point $\mathrm{M}$ creates with Ox?) - Justifying the factors to solve the problem: How many ways to write the equation lines in the plane?

(Expected result: based on the acquired knowledge, through discussion, students can identify the cases where they can write a straight line equation: 1) Passing a point and knowing the perpendicular vector; 2) Passing a point and knowing the direction vector; 3) Passing a point and knowing the coefficient of the angle; 4) Passing two distinct points); - Select the appropriate option: Teacher asks students: "In this problem, how can we write a straight line equation?". to find out students' thinking patterns, and see how they are trying to solve problems; thereby, helping students know how to convert a new problem to a familiar one, writing a straight line equation that passes through a point with a given angular coefficient.

Step 3: Presenting the solution. Teachers suggest how to present the solution to a given problem: - What is the form of an equation for a straight line passing through a point with given angle coefficient?; - Write the equation for a straight line passing through point $\mathrm{M}(1 ; 2)$ and has the coefficient $\mathrm{k}=1$ (or $\mathrm{k}=-1)$. The result of this problem offers the method to solve the problem with the following form: In the coordinate system Oxy, given the point $M\left(x_{0}\right.$; $y_{0}$ ). Write a straight line equation passing through point $M$ and cutting the axes $O x$, Oy at points $A, B$ respectively, so that $O A=k O B$ (where $k$ is a given natural number).

Step 4: Exploiting the problem: - What is the similar and general problem of the above problem? (students' expected answer: In the coordinate system Oxy, given the point $\mathrm{M}\left(\mathrm{x}_{0} ; \mathrm{y}_{0}\right)$. Write the equation for a straight line passing through the point $\mathrm{M}$ and cutting the axes $\mathrm{Ox}$, $\mathrm{Oy}$ at points $\mathrm{A}, \mathrm{B}$ respectively, so that $\mathrm{OA}=\mathrm{kOB}$ (where $\mathrm{k}$ is a given natural number); - Similar problems: i) In the coordinate system Oxy, given point A (1;3). Write an equation for line $\mathrm{d}$ passing through point $\mathrm{A}$ and intersecting the horizontal axis at $\mathrm{B}$, intersecting the vertical axis at $\mathrm{C}$ so that $\mathrm{OB}=2 \mathrm{OC}$; ii) In the coordinate system Oxy, let triangle $\mathrm{ABC}$, center of gravity $\mathrm{G}$ and $\mathrm{A}(0 ; 2), \mathrm{B}(-1 ; 3), \mathrm{C}(4 ; 1)$. The line $d$ passes through point $\mathrm{G}$ and cuts the axes $\mathrm{Ox}, \mathrm{Oy}$ at points $\mathrm{M}, \mathrm{N}$ respectively, satisfying $\mathrm{OM}=4 \mathrm{ON}$. Write the equation for the line $\mathrm{d}$.

Stage 2: Sharing and discussing. Teachers need to regularly observe students to identify their difficulties in finding solutions to such an unfamiliar problem (the problem is a construction one in nature, but requiring coordinate language to solve). Accordingly, teachers can design group discussion tasks in the form of a series of hierarchical questions using step-by-step process to find out the solution. The teacher asks students to share in groups the way to solve the problem. Through the part shared by students in groups, teachers can identify students' challenges and difficulties for timely support.

Stage 3: Self-examination and adjustment to form knowledge. The teacher asks the groups to check and correct themselves before presenting to the class.

In this step, the teacher requires the groups to present their results, other groups to comment, evaluate, and the teacher present the final answers. Teacher asks groups to give their own comments and correct their own group responses.

Stage 4: Self-applying knowledge. Teacher asks students to apply the results of the problems they have just solved and acquired knowledge to solve other problems.

Eventually, the teacher helped students to self-study with guidance in the classroom in order to practice the skills of finding solutions to a problem using G. Polya's four-step process. In each step, the teacher designed a system of questions to guide students to solve problems. Thereby, students have experienced, found the ways to solve problems by: identifying and connecting the problem, proposing, selecting, and forming solution, piloting, and making decision. Subsequently, the teacher will provide further practice for students with in another situation.

\section{DISCUSSION AND CONCLUSION}

In the process of organizing students' guided self-study, apart from designing learning activities, it is important for teachers to offer timely support to help learners overcome problems. To facilitate and instruct students with difficulty, teachers need to understand the level of learners' awareness to provide appropriate instructions, differentiate adequate learning activities so that students can address problems, construct new knowledge by themselves, especially know how to learn and self-study. To organize the implementation of self-study with guidance 
for students effectively, teachers are expected to invest considerable time amount and flexibility in the design of selfstudy guides to help them approach the problems quickly with their own capabilities.

\section{REFERENCES}

Ho Ngoc Dai (2009). Pedagogic. University of Education Publishing.

Hoang Ngoc Anh, Nguyen Duong Hoang, Nguyen Tien Trung (2017). Innovating the process of teaching Math through topics of teaching. Vietnam Education Publishing.

Hoang Phe (editor, 2018). Vietnamese Dictionary. Hong Duc Publishing.

Marzano, Robert J. (2011). Teaching science and arts (Translator Nguyen Huu Chau). Vietnam Education Publishing.

Ministry of Education and Training (2010). A new model of Colombian school.

Ministry of Education and Training (2018). General Secondary Education Program 2018 (Enclosed with the Circular No. 32/2018/TT-BGDDT, December 26, 2018 of the Minister of Education and Training).

Nguyen Ba Kim (2017). Methodology of teaching mathematics. University of Education Publishing.

Nguyen Canh Toan (2001a). Collection of self-education, self-study and self-study works (volume 1). University of Education Publishing, East-West Cultural and Language Center.

Nguyen Canh Toan, Nguyen Ky, Vu Van Tao, Bui Tuong (2001). Learning - Teaching how to learn: The process of teaching self-study. Education Publishing.

Nguyen Dinh Xuan (2000). The process of learning and self-study. Hanoi National University Publishing.

Polya, G. (2010). How to solve an exercise? Vietnam Education Publishing.

Thai Duy Tuyen (2008). Traditional and innovative teaching methods. Education Publishing.

Van Phu Quoc (2014). Training gifted Math students (part 1). Hanoi National University Publishing. 